\title{
Delivery Performance Improvement Using Six Sigma Method: A Case Study at FMC Agricultural Manufacturing
}

\author{
Satyana Primandaru ${ }^{1}$, Soeparno ${ }^{2}$ \\ Magister Management, Universitas Airlangga 60286, Indonesia \\ Industry Faculty, Sepuluh Nopember Institute of Technology 60111, Indonesia \\ satyana.primandaru-2017@feb.unair.ac.id ${ }^{1}$, suparno@ie.its.ac.id ${ }^{2}$
}

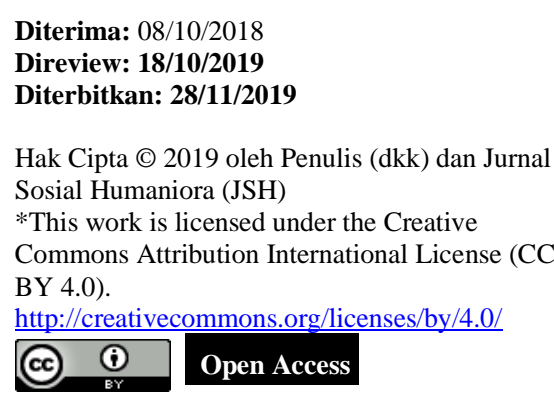

Diterima: 08/10/2018

Direview: 18/10/2019

Sosial Humaniora (JSH)

*This work is licensed under the Creative

BY 4.0).

http://creativecommons.org/licenses/by/4.0/

Open Access

\begin{abstract}
Subject Area: Economy (Ekonomi)
Abstract

PT. FMC is a manufacturing company to produce pesticides in 3 classifications: herbicides, fungicides and insecticides. The use of pesticides is very important to maintain the quality of the crop. Delivery is an important metric because delivery has big influence to customer satisfaction. The delivery of products may not be late because it will disrupt the consumer production chain. However, PT. FMC delivery performance faces a big issue. This research focuses on how companies are able to identify problems, analyze and solve these problems using the Six Sigma methodology. This method is used because the Six Sigma methodology has a cycle of how companies solve a problem that can disrupt business processes. The research found that problems in the business process are categorized into 3 causes, namely (1) delays in the arrival of material both raw material and packaging material; (2) the customer delays delivery several times; and (3) the Warehouse Leader is late in inputting data and Post Goods Issue.
\end{abstract}

Keywords: Agricultural; Manufacturing; Six Sigma Methodology; DMAIC; Delivery Performance.

\section{Introduction}

The use of basic needs from consumers increases every year and this results in high demand for raw materials from agriculture. The high demand for agricultural products requires farmers to maintain their production processes so that the quality of their products can be maximized. In a business process, there will be several factors that can make farmers fail to harvest. If farmers fail harvest, they will reduce the supply of basic needs for consumers, especially the community. One of the causes that can disrupt the production process in the field of agriculture is pests. The existence of pests in the production process will reduce productivity both in terms of quantity and quality of a product. One of the treatments needed to maintain the quality of crops is to use the right pesticides. This is because pest is one of the causes of farmers' failure to harvest.

FMC Corporation is an American company engaged in the chemical sector. FMC Corporation has various business units and one of them is in the agricultural sector. In Indonesia, there are several companies engaged in the agricultural industry sector and one of them is PT. FMC Agricultural Manufacturing. PT. FAM Indonesia has the task of producing pesticide products such as Insecticides, Fungicides and Herbicides. With the presence of pesticide products, it is expected that the quantity and quality of agricultural product will improve. In the business process, the relationship between one product to another product, or one business to 
another business is very important. One of the measurement metrics of the relationship is delivery. Delivery can be defined as a supply chain process that includes planning, implementing, controlling backflow, controlling flow, both in terms of effectiveness and efficiency, managing the movement and storage of raw goods, inventory in process, finished goods, services, and accompanying information, starting from the supplier's starting point to reaching the final consumption point in the organization and marketing channels with the aim of fulfilling consumer needs so that they can achieve the company's profit aspects (Kim J., 2000). Successful delivery will affect customer satisfaction so that delivery performance is also one of the key performance indicator (KPI) indicators in a company. Delivery can be said to be successful if the goods sent by the sender will arrive at the consumer in a timely manner from the time period desired by the consumer. When the product delivery exceeds the estimated time limit by the organization, the shipment can be said to be a miss.

PT. FMC Agricultural Manufacturing is facing the problem of Delivery Performance. At PT. FMC Agricultural Manufacturing delivery performance is divided into 2 namely Delivery to Promise (DTP) and Delivery to Request (DTR). Delivery Performance is an evaluation of KPI from the Supply Chain \& Sourcing division of PT. FMC Agricultural Manufacturing which will contribute to the assessment of customers' satisfaction. In this study, researchers will only focus more on delivery to request (DTR). This is because the assessment of delivery to request metrics is more important and has more urgency value than the delivery performance delivery metrics, namely delivery to promise (DTP). Delivery to Request is an assessment that assesses how the organization meets the sales order according to the order request and date of the customer.

\section{Literature Review}

\section{A. Six Sigma}

Six Sigma is a philosophy and methodology that has been used since 1986. This methodology is widely used by many industries because it is one tool that is powerful enough to eliminate disabilities that occur both on a product and on a process that the organization is doing. This approach focuses on making improvements and reducing variability in a process that can have an impact on quality by identifying the root causes of what affects the process. Since being introduced by Motorola for a manufacturing training program in 1988 Six Sigma has developed into an extension of total quality management (TQM) (Green, 2006).

As a project-based management approach, the Six Sigma application series also develops from the production process to become a business strategy that focuses on increasing understanding of customer needs, business capabilities and financial performance (Kwak and Anbari, 2006). Six Sigma processes are a customer- oriented, structured, systematic, proactive and quantitative approach to continuous process improvement in an organization's business processes to ensure quality improvement, low cost and fast delivery, and drive waste from business processes using tools and technical statistics (Breyfogle and Cupello, 2001; Harry and Schroeder, 2000). The application of Six Sigma in the company will have a good impact both for the company itself and for the consumers or suppliers of the company. One of the benefits received from the application of the Six Sigma cycle is how this cycle requires managers to be able to read errors made in business processes carried out by the organization and can compare the process whether it runs 
perfectly or not using a metric called defects per million opportunities (DPMO), in which calculation of the metric requires 3 types of data, namely Unit, Defect, and Opportunity.

In making an improvement, the company will need tools that they can use according to the needs of their own company. By applying suitable tools, it will benefit the company both from the time needed to make a process improvement, up to the cost benefits. Broadly speaking, the Six Sigma goal of making improvements is (1) reducing the cost of rework or repair, (2) reducing the cost of improving productivity (3) growing market share, (4) reducing cycle times, (5) customer retention, (6) minimize defects, (7) changes in work culture and (8) develop service products. Based on the explanation of the application of Six Sigma, it is expected that the method will function well in an improvement, so that the company will also have a positive impact (Pande, 2002).

\section{B. DMAIC}

Six Sigma has 5 stages abbreviated as DMAIC (Defect, Measure, Analyze, Improve and Control). The application of one of these elements must have an impact to the bottom line and also to customer satisfaction (Anthony, 2006).

\section{1) DEFINE}

In define phase, the management of the company must clearly identify the problems faced and determine the resources needed to make improvements. In the define phase, there are several steps that must be taken, namely:

(1) determine the problems that you want to make the project both in a concise and specific manner, (2) perform a simple mapping of the process both up and down to determine where the problem lies, (3) establish input, output and various process control processes, (4) clearly describe the role of people and their responsibilities for the project in the six Sigma project charters, (5) be able to identify all consumers both internally and externally and also determine how these problems will be related to customer satisfaction (Anthony, 2006).

\section{2) MEASURE}

In measure phase, researchers measure the amount of deviation that occurs compared to the quality standards that have been set from the product or process that you want to repair. The followings are some items that must be considered in conducting the measure stage in the six sigma methodology: (1) determining the performance of the service process at this time (process yield, DPMO, short-term, and long-term capability), (2) determining what is to be measured (critical to quality characteristic - CTQ) and how to measure it, (3) making a measurement study system simple, (4) identifying strengths and weaknesses and also what gaps can interfere with the improvement process (Anthony, 2006).

\section{3) ANALYZE}

Analyze phase is to identify the factors that cause the occurrence of irregularities, and conduct an analysis of root cause problems that occur in a business process. The following are some important points that must be considered in working on the analyze phase in the six sigma methodology: (1) fingding the root cause defect of a process in both business processes and production processes or other processes, (2) 
understanding the various variations of root cause problems that cause further investigation to resolve defects in a process, (3) understanding the data and distribution of the data and the pattern of the data also, (4) understanding $\mathrm{g}$ what is the key to service process variables that might be related to defects in a process, (5) calculating the possibility of financial opportunity development (estimating the potential financial benefits obtained by doing improvement) (Anthony, 2006).

\section{4) IMPROVE}

After the researcher performs analysis in Analyze phase, he will formulate improvement solutions and key variables in a production process. In the improvement phase, the following issues must be considered: (1) develop potential solutions to solve existing problems and also protect them so that they do not recur, (2) provide solutions that have a major impact on companies or organizations to be able to improve customer satisfaction and bottomline savings and determine how time, effort and capital is needed to carry out the implementation, (3) assess the risks associated with potential solutions, (4) validate improvements with pilot studies (reducing defect rates or increasing sigma quality levels in a process), and (5) reevaluate the impact of potential solutions that have been chosen by the company (Anthony, 2006).

\section{5) CONTROL}

Control phase is the last step taken to monitor the impact of the remedial solutions that have been made. Periodically, it is necessary to monitor changes that occur so that they can be sustainable. In the control phase, it should be focused on the items below: (1) develop corrective action to maintain the level of service process performance that has been developed, (2) develop new standards and new procedures to gain long-term benefits, (3) implement process control plans and also know the capabilities of a process model, (4) identify or verify every benefit, cost savings that can be obtained from any improvements that have been made by the company, (5) close the project, and also complete the documentation and provide key lessons that have been learned from the project that has been done, and (6) publish the results of research or projects internally or externally and understand the contributions that the team members have given (Anthony, 2006).

\section{Research Method}

The review of the research methodology includes several consecutive explanations ranging from the type of research, the types and sources of research data, technical data collection, data processing techniques, data analysis techniques, and data interpretation techniques. Here's a review of the details

Research usually has sources and types of data, both primary and secondary data. To get accurate results, the researcher must be able to determine what type of data is appropriate to be used in the discussion of this study and this research is a research using descriptive - explorative in qualitative method. This is based on researchers who use investigations and also conduct data processing in the field, exploring summary reports, expecting objectivity and validity from the data.

This study uses both primary data and secondary data to support the validity of the study. Primary data in this study are data obtained directly from the source or field based on written document at the factory and related parties such as Operations Manager, Supply Chain Manager, Warehouse Leader, Export-Import Leader, Material Scheduler, and also several other employees and direct observations about the state and 
business processes at PT. FMC Agricultural Manufacturing. The secondary data in this study are obtained from literature studies, books related to the Six Sigma DMAIC method, journals about defects in manufacturing companies, as well as internal data from PT. FMC Agricultural Manufacturing associated with a general description of the object of research, organizational structure, data on the number of shipments, the value of the delivery performance metric and the number of shipments that failed to meet the delivery target in accordance with what has been requested by consumers and also recorded in the system.

The research phase is built on the basis and value of the concepts reviewed in this research journal by determining the research approach and strategies used, so that the analysis and results of thought obtained can then be used as material for making decisions. In this study researchers used a six sigma approach. According to Anthony (2006) Six Sigma has 5 stages abbreviated with DMAIC (Defect, Measure, Analyze, Improve and Control).

Figure 1 Flowchart Research Stage

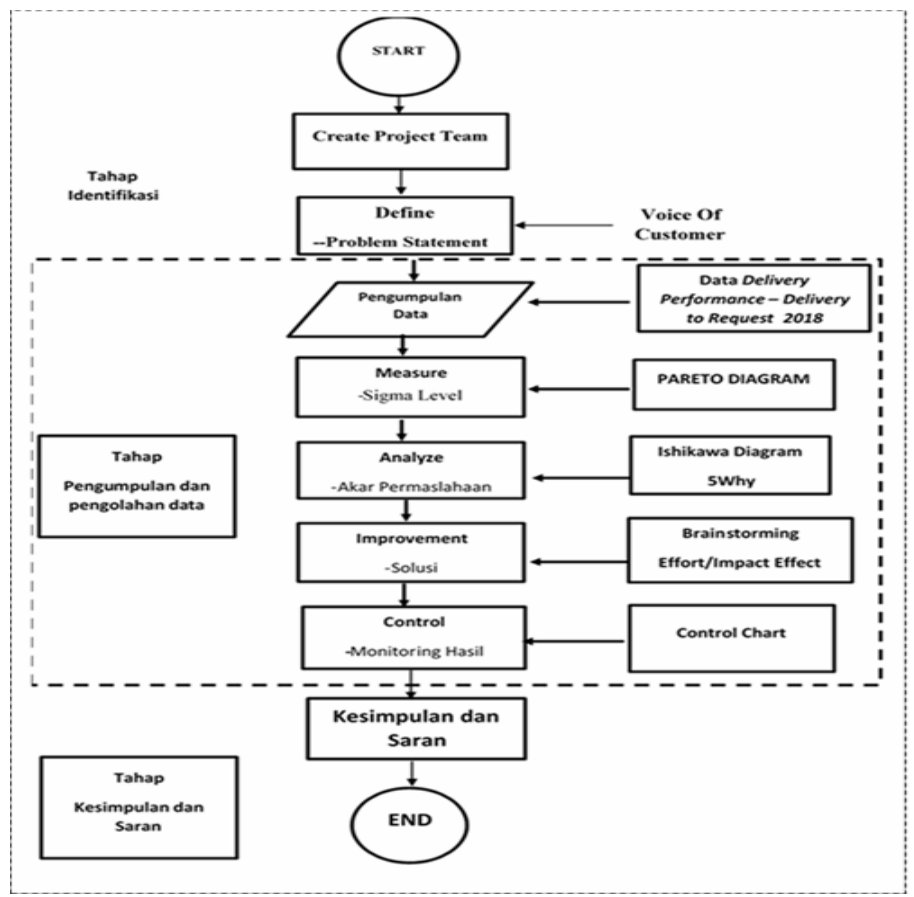

The steps taken in working on the Six Sigma DMAIC method must be clearly defined what is the problem that is happening (D), performed calculations (M) whether the defect is very responsible for the problem, carried out data analysis (A) to look further about the root causes of the problem, after analyzing the defect and the root of the problem. The next step is to do Improvement (I) of the process to minimize and even reduce to eliminate the root causes of the defects that cause problems in the business process. The last step is Controlling (C) or can be said to be monitoring the processes that occur to prevent the problem from settling for long and difficult to identify and solve.

\section{Data Collection Technique}

The study has various ways of collecting data, and in this study the data collection procedures were carried 
out as follows:

\section{Preliminary Study}

During the preliminary study process, the researcher got an overview and found that there were problems in the business process in the delivery metrics at PT. FMC Agricultural Manufacturing.

\section{Literature Study}

In this research, the source of literature used are journals and books related to quality control, Six Sigma, and quality management. This literature study is used to deepen the writer's knowledge about the problem to be studied and to compile the theoretical basis used in literature review in research.

\section{Field Study}

Field Study is carried out by visiting the object of research and collecting data that can be used in research using the following techniques.

\section{a. Observation}

Observation is a method of data collection by directly observing operational activities that are being carried out in PT. FMC Agricultural Manufacturing

\section{b. Documentation}

Documentation is the collection of data derived from documents written in companies that can support the research conducted. Documents can be in the form of pictures or writing. Company documents or data needed in this study are data on the number of shipments that failed on time in 2018.

\section{Research Scope}

The research scope is a limitation of research in which there are limitations to the problem so that research is more focused on the subject matter. Limitation problems of this study are as follows:

4. This research was conducted at an Agricultural company in PT. FMC Agricultural Manufacturing Indonesia.

5. This research focuses on what business processes are factors that will affect delivery performance.

6. The research object used is the product of PT. FMC Agricultural Manufacturing.

7. The study was conducted on shipments that miss or do not match the date that was desired by the consumer.

\section{Result and Discussion}

Data Analysis and Interpretation with DMAIC stages:

a) Define Phase is a stage that requires researchers to determine the root cause or defect critically what happens to the business process. In this study the main root cause is the occurrence of problems in the delivery performance metrics of PT. FMC Agricultural Manufacturing. This problem can be seen in Figure 1.1. Next, the researcher will make a repair solution so that it can reduce the root cause effect that causes critical defects. In phase control, the researcher monitors the impact of repairs on the remedial solutions that have been made to one group for 90 working 
days. The monitoring process is carried out using a control chart. From the results of monitoring, it is known that the number of critical defects occur in the production process after implementing a repair solution. The researcher will again do the calculation using Minitab and compare the results before and after making improvements. Delivery performance for delivery to request was in 2018. From the data it is seen that the delivery performance in 2018 is $85 \%$, but the achievement of delivery performance is still below the standard determined by FMC Corporation, which is equal to $90 \%$.

b) Measure Phase will explain how management measures the amount of irregularities that occur compared to the quality standards that have been set from the product or process that is needed to improve. In this study, researchers used Minitab 18.

Figure 2: Data Probability for DTR

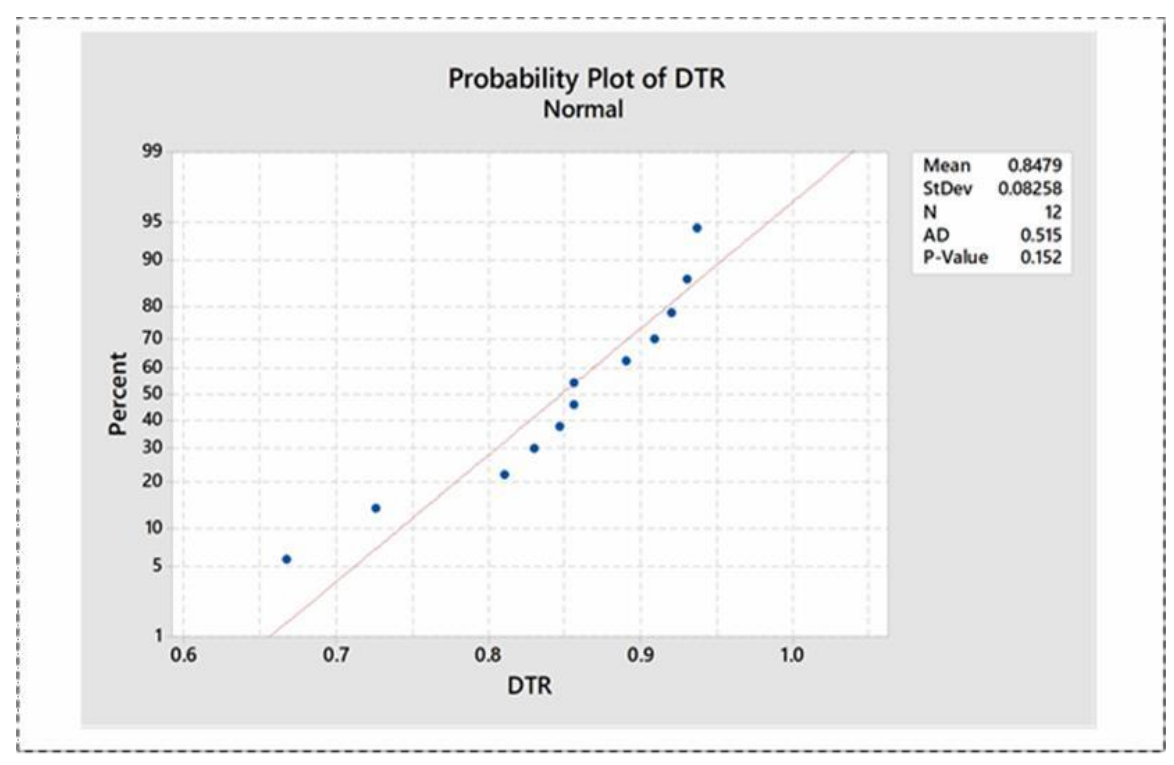

Figure 2 is a probability plot data for DTR that shows how the data owned by PT. FMC has been normally distributed and this can be seen from the value of P. Value which has a value of 0.152 indicates that the data has been normally distributed and there is no data outlayer due to special conditions so that no data needs to be removed because of the outlayer value. 
Figure 3: Process Capability Report for DTR

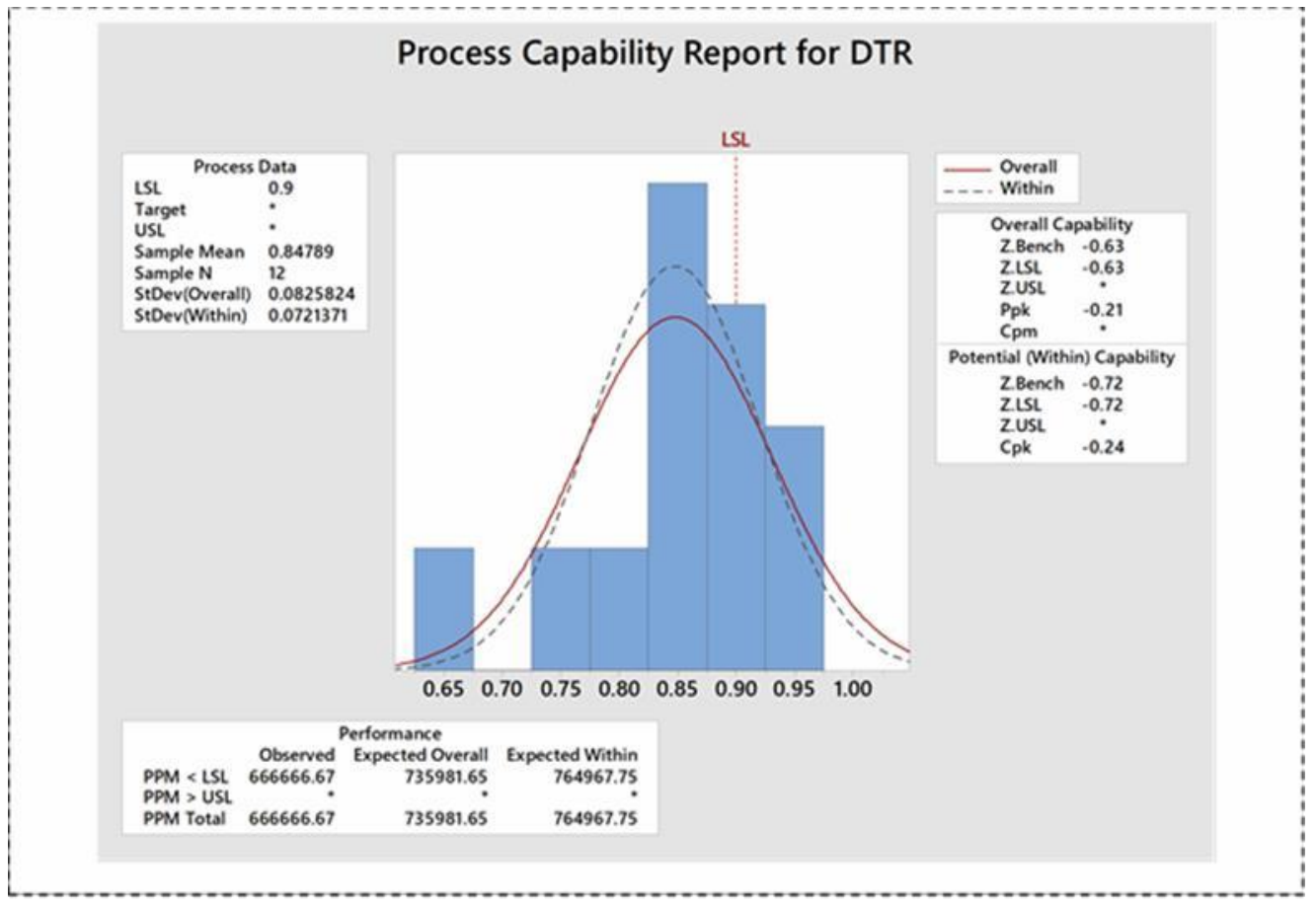

Figure 3 is a Data Process Capability Report for DTR. The data explains the sigma level which can be seen from the value of Z. Bench, and it can be seen from the Data Process Capability Report that PT. FMC Agricultural Manufacturing has a Z. Bench value of -0.63 . The data shown by $\mathrm{Z}$. Bench is a measurement of the sigma value in the process and that there are various defects that make the delivery performance measurement metric less effective.

Figure 4 Summary Report for DTR

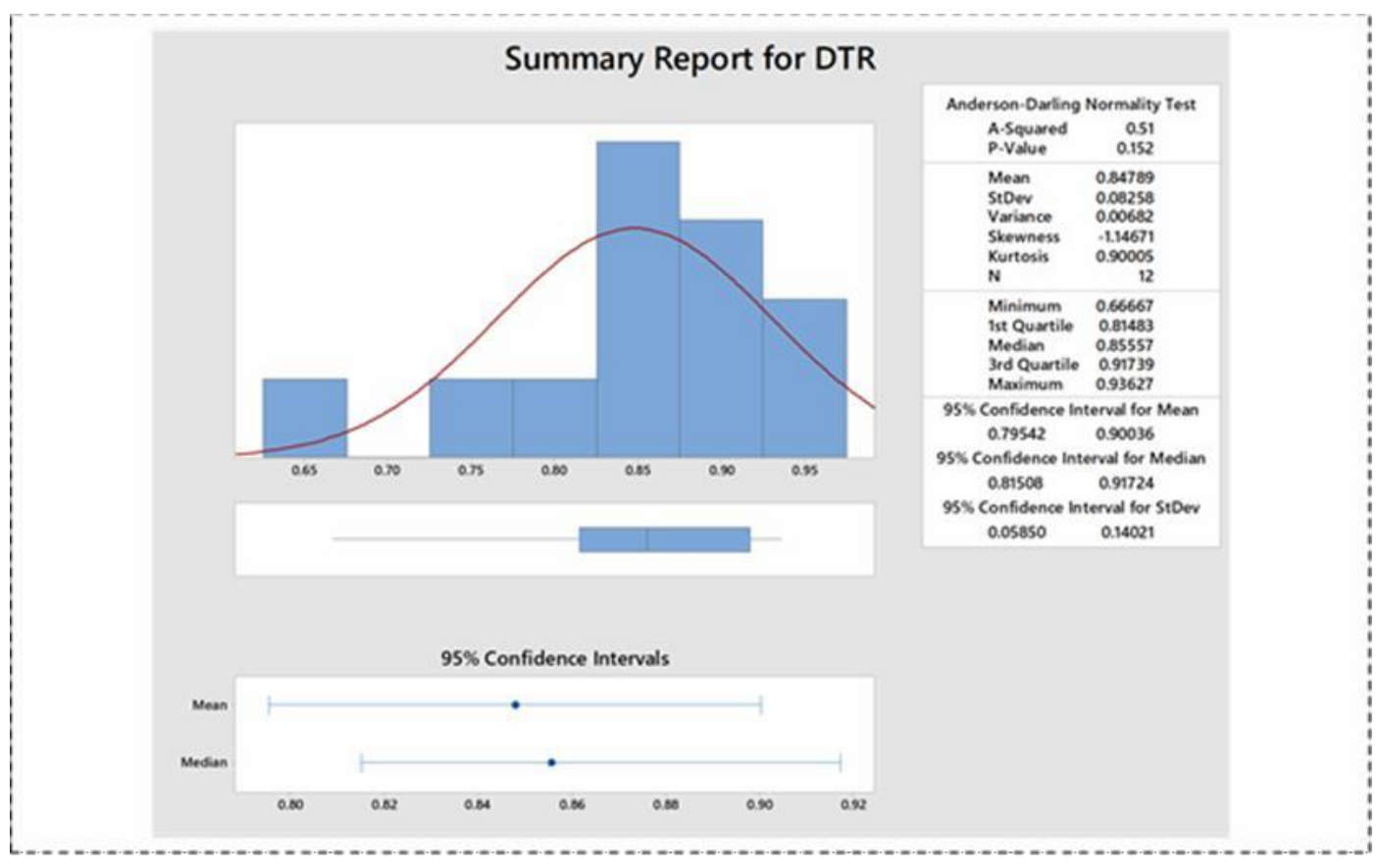


Figure 4 is a Summary Report Data for DTR that shows the results of the calculation of data Delivery to Request PT. FMC Agricultural Manufacturing. In this summary report, it can be seen from the interval confidence for mean and confidence interval for median which indicates that if the business process in the delivery to request metric does not change and increase then in the future the value will not exceed the $0.79542(79.45 \%)$ to $0.90036(90.03 \%)$. So, from these calculations it is highly recommended to carry out a project charter in order to increase the value of delivery performance, namely delivery to request.

c) Analyze Phase is a stage that requires researchers to identify the causes of irregularities and what factors influence the measurement of delivery performance values. Figure 4.1 is Pareto from the rootcause failure analyze data PT. FMC Agricultural Manufacturing that is based on delivery performance review report data in 2018. The main causes of the problems in the delivery or delivery process are explained in Figure 5. To reach 80\% in the Pareto Chart 5 Root Cause it needs (1) AVL1R, Material Availability/Supply issue, (2) CRH1, Credit Hold BUS3 is Consolidated Orders, and (3) SHP6 is Delayed GI. However, the process will only be focused on 3 factors because the scope is focused on the company's operational scope, not the scope of the company's business. This is because the main key performance indicator (KPI) in customer satisfaction in delivering goods on time to consumers is from the company's operational scope.

Figure 5 Pareto Char for DTR

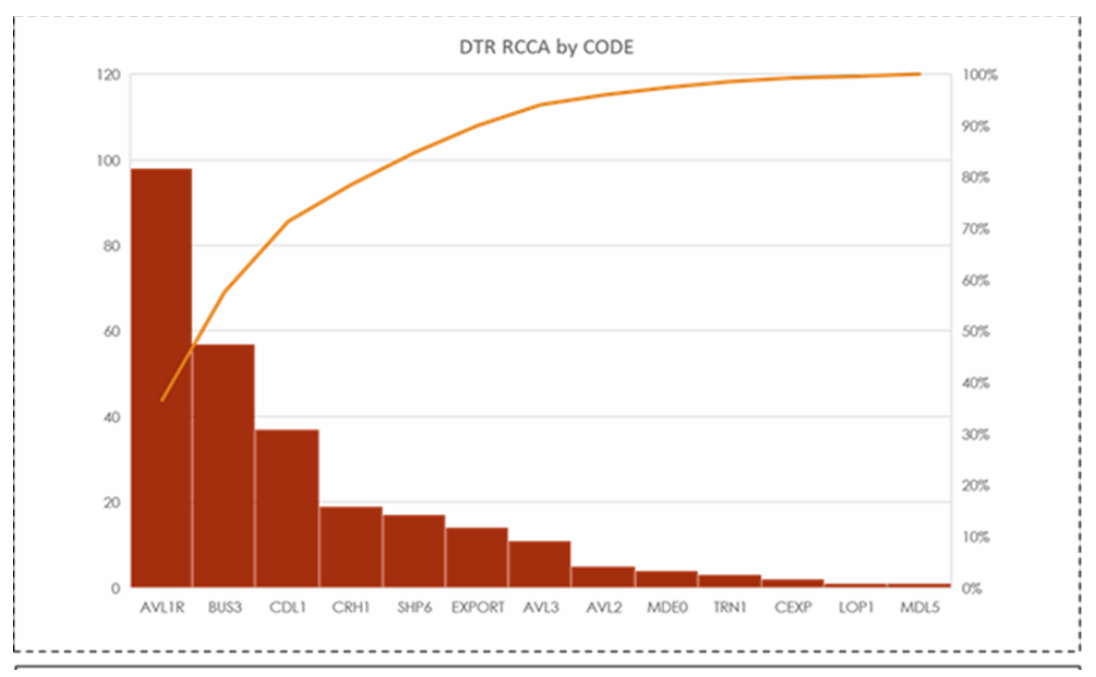

d) Improve Phase is a stage where researchers have known the main causes of problems in the delivery performance metrics at PT. FMC Agricultural Manufacturing, and 3 main causes, namely (1) AVL1R is Material Availability / Supply issue, (2) BUS3 is Consolidated Orders, (3) SHP6 is Delayed GI. After knowing the problems that occur in the delivery performance metrics, the researcher will do the next stage on Six Sigma DMAIC, namely the Improve stage. In the improve phase, suggestions will be given on what can be done to improve, minimize and avoid the problem so that it does not happen again. The focus of improvements will be given to PT. 
FMC Agricultural in accordance with problem code which has a major contribution in delivery performance metrics, which can be seen from the table below.

Table 1 Delivery performance metrics

\begin{tabular}{|c|c|c|}
\hline \begin{tabular}{|l|} 
PROBLEM \\
CODE \\
\end{tabular} & ROOT CAUSE PROBLEM & CORRECTIVE ACTION \\
\hline \multirow[t]{2}{*}{ AVL1R } & $\begin{array}{l}\text { Material Planner has not used } \\
\text { the SAP system to its full } \\
\text { potential and often does not } \\
\text { follow up on outstanding PO } \\
\text { to suppliers }\end{array}$ & $\begin{array}{l}\text { Material Planner must update frequently regarding the } \\
\text { conditions that are occurring in the field to measure order } \\
\text { leadtime and make it easier for planner material to follow up } \\
\text { with suppliers and find out specific times when to reorder. } \\
\text { Developing a Kanban strategy to measure packaging } \\
\text { material requirements and re- order before the packaging } \\
\text { material is used up }\end{array}$ \\
\hline & $\begin{array}{l}\text { Packaging Material orders by } \\
\text { planner materials only rely on } \\
\text { one supplier, so the supplier } \\
\text { bargaining power is very } \\
\text { strong }\end{array}$ & $\begin{array}{l}\text { Providing one additional supplier to be able to support a single } \\
\text { vendor to meet the material needs of production and } \\
\text { packaging PT. FMC Agricultural Manufacturing }\end{array}$ \\
\hline \multirow[t]{2}{*}{ BUS3 } & $\begin{array}{l}\text { Small-scale consumer product } \\
\text { orders are divided into 3: } \\
\text { sample, bonus, and small- } \\
\text { scale order consumers }\end{array}$ & $\begin{array}{l}\text { - Conduct a separation of orders on a small scale, i.e. between } \\
\text { samples and bonuses with consumers who actually order on a } \\
\text { small scale, this is because bonuses and samples are not } \\
\text { mandatory and are included in the customer satisfaction } \\
\text { calculation. }\end{array}$ \\
\hline & $\begin{array}{l}\text { Small-scale shipping requires } \\
\text { special requirements, namely } \\
\text { by using LCL, but the contract } \\
\text { to use LCL will be done when } \\
\text { it will be needed }\end{array}$ & $\begin{array}{l}\text { - The Sourcing and CSR division make a cooperation contract } \\
\text { with the Transportation Party which becomes a supplier in } \\
\text { small- scale shipments or by using LCL, to determine the } \\
\text { delivery leadtime requirements of CSR and also see the } \\
\text { cost } \\
\text { - factors and LCL usage requirements from sourcing }\end{array}$ \\
\hline \multirow[t]{2}{*}{ SHP6 } & $\begin{array}{l}\text { Warehouse Leaders delayed } \\
\text { entering Goods Issues in SAP } \\
\text { because the Delivery Note } \\
\text { made by the Supply Chain is } \\
\text { late }\end{array}$ & \multirow[t]{2}{*}{$\begin{array}{l}\text { - Followed up the PO outstanding a week before the due date } \\
\text { to make delivery planning so that it is not too late to enter } \\
\text { PGI and also not be late in making transportation orders to } \\
\text { send products to consumers }\end{array}$} \\
\hline & $\begin{array}{l}\text { Transportation needed to send } \\
\text { goods that will be sent to } \\
\text { consumers is not available due } \\
\text { to Delivery Notes that are made }\end{array}$ & \\
\hline
\end{tabular}

e) Control Phase is the last stage of the Six Sigma DMAIC method. In the Controlling (C) stage, the researcher must be able to monitor the processes that occur to prevent the problem from remaining long and difficult to identify and solve. At this stage, data sampling will be taken for the next 3 months and viewed based on the value of the delivery to request metric. During the monitoring process, it is expected that the problems that become the root cause resulting in late delivery will be minimized and in the future it can be eliminated so that the corrective action expected by the researchers will have a positive impact on delivery performance metrics that will impact on the increasing customersatisfaction. 


\section{Conclusion and Suggestions}

A. Conclusion

1. From the analysis stage, it is defined that PT. FMC Agriculture Manufacturing has an estimated shipping performance value of shipping to request in 2018 at $85 \%$ of the target at $90 \%$.

2. From the analysis of the data at the measurement stage using Minitab and Figure 4, it can be seen that the shipping performance by PT. FMC Agriculture Manufacturing has a value of Z.Bench $-0.63 \partial$ of the highest standard value $\partial$ is 6 . This data describes what makes defects that make shipping performance evaluation metrics less effective.

3. Based on data analysis in the Analysis phase using Pareto tool to find rootcause and to reach $80 \%$ in Pareto Chart 5 Root Cause, some steps namely (1) AVL1R is a matter of Availability of Material/Supply, (2) CRH1 is Credit Hold BUS3 is an Order Consolidation, (3) SHP6 is Delayed GI are needed. But that will only focus on 3 factors because the scope of focus is the company's operational scope, not the company's business scope. This is because the main key performance indicators (KPI) in customer satisfaction in delivering goods on time to consumers are from the scope of the company's operations.

4. The company has problems with human labor and also existing procedures. Moreover, the companies should more often audit several companies that have a big hand in supporting the delivery of this because some companies understand about the procedure but do not require procedural and provide a bypass warning that is done so that it can be discussed appropriately when opening material or wrong input by employees.

\section{B. Suggestions}

1. To be able to reduce the risk of mistakes by employees repeatedly, there must be strict supervision by management. This is because if there is no change in enforcement of employees, employees will always work in the same culture and not change. Then, the change in work procedures will not work as it is supposed to. Moreover, improvements to the $5 \mathrm{~S}$ system to be more efficient are needed by reducing the potential for 7 Waste so that the company can work and run effectively and efficiently.

2. One of the strategies that may be carried out by companies that discuss with the material to able to calculate the potential late is with the kanban system. However, the new kanban system can be used properly if the company applies $5 \mathrm{~S}$ properly and correctly 


\section{References}

Andersen, B. 2007. Business Process Improvement Toolbox. ASQ Quality Press, Milwakuee.

Antony, J. (2002), "Design for Six Sigma: a breakthrough business improvement strategy for achieving competitive advantage", Work Study, Vol. 51 No. 1, pp. 6-8

Antony, J. (2006), “Six Sigma for service processes”, Business Process Management Journal,Vol. 12 No. 2, pp. 234-48.

Ferrin, D., Miller, M. and Muthler, D. (2005), "Lean sigma and simulation, so what's the correlation? V2", Proceedings of the 2005 Winter Simulation Conference, Orlando, FL, 4-7 December, pp. 201115.

Green, F.B. (2006), "Six-Sigma and the revival of TQM", Total Quality Management \& Business Excellence", Vol. 17 No. 10, pp. 1281-6.

Hadidi, Laith A., Abdulaziz Bubshait, Suleiman Khreishi. 2017. Six Sigma for Improving Aesthetic defects in Aluminum Profiles Facility. Facilities Vol. 35 No. 3/4 . Emerald Insight.

Jirasukprasert, Plotyp., Jose Arturo, Vikas Kumar and Ming K. Lim. 2014. A Six Sigma and DMAIC application for the reduction of defects in a rubber gloves manufacturing process. International Journal of Lean Six Sigma,Vol 5 lss 1 pp. 2 - 21.

Kumar, M., Antony, J., Antony, F.J. and Madu, C.N. (2006), "Winning customer loyalty in an automotive company through Six Sigma: a case study", Quality Reliability Engineering International, Vol. 23, pp. 849-66.

Kotler, Philip. 2005. Manajemen Pemasaran, Edisi 11 jilid 1 dan 2 Pemasaran, Jakarta: PT. Indeks,Jakarta.

Kwak, Y.H. and Anbari, F.T. (2006), "Benefits, obstacles and future of Six Sigma approach", Technovation, Vol. 26 Nos 5-6, pp. 708-15.

Prashar, A. 2014. Adoption of Six Sigma DMAIC to reduce cost of poor quality. International Journal of Productivity and Performance Management. Vol. 63 No. 1, pp. 103-126

Thomas Pyzdek. 2001. The Six Sigma Handbook. New York:Mc Graw-Hill.

Watson, G.H. and deYong, C.F. (2010), "Design for Six Sigma: caveat emptor", International Journal of Lean Six Sigma, Vol. 1 No. 1, pp. 66-84. 